\title{
Ouratea lancifolia R. G. Chacon \& K. Yamam. (Ochnaceae), uma nova espécie do Cerrado, Brasil ${ }^{1}$
}

\author{
ROBERTA GOMES CHACON ${ }^{2,5}$, KIKYO YAMAMOTO ${ }^{3}$ e TACIANA BARBOSA CAVALCANTI ${ }^{4}$
}

(recebido: 01 de junho de 2011; aceito: 02 de dezembro de 2011)

\begin{abstract}
Ouratea lancifolia R. G. Chacon \& K. Yamam. (Ochnaceae), a new species from Brazilian savanna) The new species Ouratea lancifolia R. G. Chacon \& K. Yamam. is described. It comprises small shrubs from grassy savannas and is characterized by lanceolate leaves with cordate base and serrate margins. Description, illustration, and ecological comments are presented. Distinctions between the new species and its two closest species, O. lanceolata (Pohl) Engl. e O. floribunda (A. St.-Hil.) Engl., also from the Cerrado biome, are pointed out.
\end{abstract}

Key-words - Brazil, grassy savanna, taxonomy

RESUMO - (Ouratea lancifolia R. G. Chacon \& K. Yamam. (Ochnaceae), uma nova espécie do Cerrado, Brasil) A nova espécie Ouratea lancifolia R. G. Chacon \& K. Yamam. é descrita. Ela compreende arbustos pequenos de savana gramíneo-lenhosa e se caracteriza pelas lâminas foliares lanceoladas de base cordada e margens serreadas. São apresentados descrição, ilustração e comentários ecológicos. São analisadas as diferenças em relação às duas espécies mais próximas, O. lanceolata (Pohl) Engl. e O. floribunda (A. St.-Hil.) Engl., também ocorrentes no bioma Cerrado.

Palavras-chave - Brasil, savana gramíneo-lenhosa, taxonomia

\section{Introdução}

Ouratea Aubl., gênero de distribuição pantropical (Engler 1876), é o mais diverso da família Ochnaceae. Compreende aproximadamente 300 espécies (Fiaschi et al. 2011), 70\% das quais na América tropical. $\mathrm{Na}$ revisão mais importante sobre as espécies neotropicais de Ouratea, Engler (1876) reconheceu 85 espécies, a maioria delas ocorrentes no Brasil. Hoje, 121 espécies válidas são registradas no país (Chacon \& Yamamoto 2010). Durante estudos realizados nos últimos 10 anos com a família, principalmente no Brasil Central (Chacon et al. 2003, Yamamoto et al. 2008), foram registradas populações de uma nova espécie em áreas de Cerrado em Goiás, Mato Grosso, Mato Grosso do Sul e Minas Gerais. Esta nova espécie é descrita, ilustrada e comentada no presente trabalho.

1. Parte da dissertação de mestrado da primeira autora, Programa de Pós-Graduação em Botânica, Universidade de Brasília, Brasília, DF, Brasil.

2. Universidade de Brasília, Campus Universitário Darcy Ribeiro, Instituto de Ciências Biológicas, Departamento de Botânica, Asa Norte, 70910-000 Brasília, DF, Brasil.

3. Universidade Estadual de Campinas, Instituto de Biologia, Departamento de Biologia Vegetal, Rua Monteiro Lobato 970, Cidade Universitária “Zeferino Vaz" Barão Geraldo, Caixa Postal 6109, 13083-970 Campinas, SP, Brasil.

4. Embrapa Recursos Genéticos e Biotecnologia, Parque Estação Biológica - PqEB, Av. W5 norte (final), Caixa Postal 02372, 70770917 Brasília, DF, Brasil.

5._Autora para correspondência: rgchacon@gmail.com

\section{Resultados e discussão}

Ouratea lancifolia R. G. Chacon \& K. Yamam. Tipo: BRASIL. GoIÁs: Mineiros, Parque Nacional das Emas, entre $17^{\circ} 50^{\prime}$ e $18^{\circ} 15^{\prime} \mathrm{S}, 52^{\circ} 30^{\prime}$ e $53^{\circ} 10^{\prime} \mathrm{W}, 800-900 \mathrm{~m}$, 27-I-1991, Giordano et al. 926 (Holótipo RB).

Figura 1

Ab Ouratea lanceolata (Pohl) Engl. foliis marginibus serratis (non integris) et basi cordatis (non obtusis) differt. Item distincta prae Ouratea floribunda (A. St.-Hil.) Engl. foliis in apicibus ramulorum lanceolatis vel ellipticis (non oblongis vel ellipticis), basi cordatis (non obtusis), inflorescentia glabra, bracteis $0,8 \mathrm{~mm}$ (non 2,5 mm) latis, bracteolis persistentibus 2-2,5 mm (non 3,5 mm) longis, alabastris minoribus 4-5 mm (non 8,5 mm) longis, petalis minoribus $7 \mathrm{~mm}$ (non $10 \mathrm{~mm}$ ) longis, antheris rugulosis 5-5,5 mm (non 6-7 mm) longis sed rugis laevibus, stylo 4-5 $\mathrm{mm}$ (non 6-6,5 $\mathrm{mm}$ ) longo.

Arbustos 30-45 cm alt.; ramos marrons ou acinzentados, estriados longitudinalmente, não esfoliantes, glabros, geralmente com lenticelas. Estípulas $5,5-9(-11) \times 1 \mathrm{~mm}$, triangulares, estriadas longitudinalmente, geralmente caducas. Folhas 6,5-12 $\times$ 1,3-2,8 cm, coriáceas, brilhantes em ambas as faces, glabras, marrons em material herborizado; pecíolos 1,5$2 \times 2 \mathrm{~mm}$, crassos, não sulcados na face adaxial, lâminas lanceoladas, às vezes elípticas, base cordada, às vezes aguda ou obtusa nas folhas dos ramos apicais, ápice agudo, mucronado, margem plana, serreada, raramente 
com margem inteira no mesmo indivíduo, nervuras primária e secundárias proeminentes em ambas as faces, nervuras terciárias horizontais paralelas. Panículas piramidais ou raramente com eixos laterais curtos dando aspecto racemiforme, terminais ou subterminais, isoladas ou em grupo de dois ou mais; eixo principal 5,5-16,5 cm compr., glabro, eixos laterais 4-7 cm compr.; cimeiras 1-3 flores; brácteas 4-5 ×0,8 mm, triangulares, agudas, caducas; bractéolas 2-2,5 $\times 0,5 \mathrm{~mm}$, lineares, aos pares, persistentes; pedicelos 6-12 mm compr., glabros. Botões florais 4-5 × 2,5 mm, ovais, ápice agudo, glabros; sépalas 6-7 $\times 2-3 \mathrm{~mm}$, ovais e lanceoladas, glabras, cedo caducas;

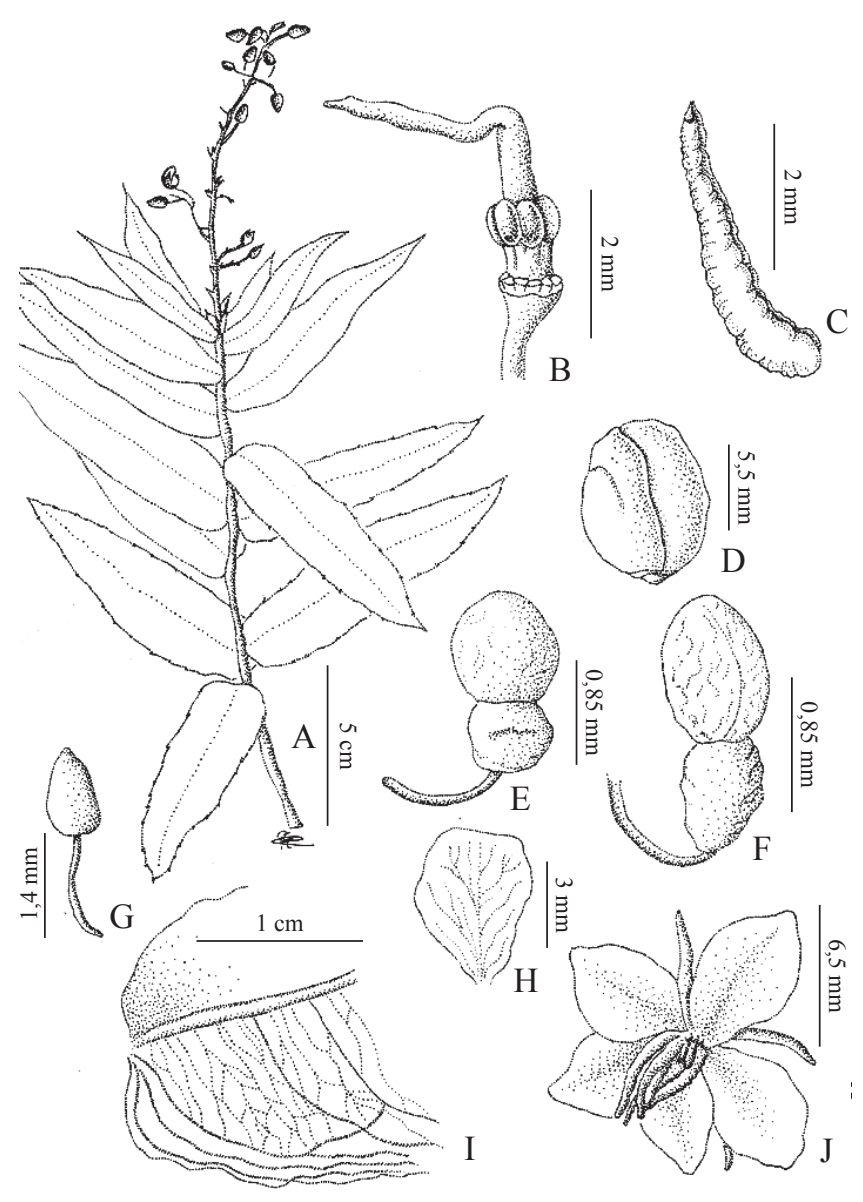

Figura 1. Ouratea lancifolia R. G. Chacon \& K. Yamam. A. Ramo. B. Gineceu. C. Antera. D. Embrião. E-F. Fruto maduro. G. Botão floral. H. Pétala. I. Folha: detalhe das nervuras. J. Flor. (A-C, G-H: Giordano et al. 926; D-E: Paula-Souza 8235; H: Ferreira 3024).

Figure 1. Ouratea lancifolia R. G. Chacon \& K. Yamam. A. Branch. B. Gynoecium. C. Anther. D. Embryo. E-F. Ripe fruit. G. Flower bud. H. Petal. I. Leaf: detail of venation. J. Flower. (A-C, G-H: Giordano et al. 926; D-E: Paula-Souza 8235; H: Ferreira 3024). pétalas $7(-9) \times 4 \mathrm{~mm}$, obovais ou oboval-orbiculares; anteras 5-5,5 mm, transversalmente rugulosas, rugas sem protuberâncias; gineceu 5-carpelar, ginóforo 0,5-1 mm compr., cilíndrico; carpelos 0,5-1 mm, oblongos; estilete 4-5 mm. Carpóforos 4-10 × 4-5 mm, globosos ou obpiriformes, pedúnculos glabros; mericarpos 6-10× 4-6 mm, oblongos, raramente obovais; sementes com cotilédones oblongos, de tamanhos iguais, ápice arredondado, sem apêndice laminar.

Material adicional examinado: BRASIL. GoIÁs: Aporé, 1957' S, 5201' W, 16-VI-1995, Pietrobom da Silva 2339 (MBM). Caçu e São Simão, UHE Salto do rio Verdinho, $1^{\circ} 54^{\prime} \mathrm{S}, 50^{\circ} 51^{\prime} \mathrm{W}, 29-\mathrm{VIII}-2008, F$. Guilherme et al. 1268 (CEN, HJ). Chapadão do Ceú, Parque Nacional das Emas, 11-X-2006, J. Paula-Souza et al. 8235 (SPF); Parque Nacional das Emas, $21 \mathrm{~km}$ do portão Jacuba, 11-X-2006, J. Paula-Souza et al. 8356 (SPF). Jataí, estrada de Jataí para Serranópolis, 16-III-1973, J. Rizzo 9158 (CEN); 41 ${ }^{\circ}$ BIMTZ, 05-XI-2004, L. Souza 3303 (CEN, HJ); 41ํBIMTZ, 14-VIII-2000, L. Souza 881 (CEN, HJ). Mineiros, 20-V-1991, H.D. Ferreira 2300 (UFG); Parque Nacional das Emas, V-1995, H.D. Ferreira 3924 (UFG); Parque Nacional das Emas, 15-1-1995, V. Klein 2662 (CEN, UFG); Parque Nacional das Emas, 16-II-1995, R. César 273 (CEN); Parque Nacional das Emas, 13-I-1991, A.L. Brochado 159 (IBGE); Parque Nacional das Emas, 12-III1990, H.D. Ferreira 2214 (CEN, UFG). Mato Grosso: Alto Garças, 17-X-1997, M. Macedo et al. s.n. (UB). Mato Grosso do Sul: Campo Grande, 17-IX-1986, C. A. Conceição 1939 (UEC); Fazenda Santa Inês, 15-X-1989, U. M. Resende 53 (UEC); Campo Grande, 02-IX-1989, C. A. Conceição 1939 (UEC). Minas Gerais: Iturama, 04-VII-1978, H. F. Leitão Filho et al. 8133 (UEC); Três Lagoas, 16-IX-1964, J. C. Gomes Jr. 2120 (UB); Três Lagoas, 17-IX-1964, J. C. Gomes Jr. 2140 (UB).

Ouratea lancifolia foi coletada em campo sujo e campo cerrado, em áreas de savana gramíneo-lenhosa, a $800-900 \mathrm{~m}$ de altitude em Goiás, Mato Grosso, Mato Grosso do Sul e Minas Gerais. De acordo com as categorias e critérios da IUCN (2003) esta espécie pode ser considerada como LC (Least Concern) tendo em vista que uma de suas populações ocorre no Parque Nacional das Emas, Unidade de Conservação integral.

Ouratea lancifolia se assemelha a $O$. lanceolata (Pohl) Engl. por ambas apresentarem hábito arbustivo, folhas lanceoladas e muitas nervuras terciárias (intersecundárias) paralelas. Além disso, as espécies são simpátricas. No entanto, Ouratea lancifolia possui lâminas foliares com margens totalmente serreadas, base 
cordada (às vezes aguda ou obtusa nas folhas dos ramos apicais e, nestes casos, os ramos inferiores apresentam folhas com base cordada) e com as superfícies foliares brilhantes, enquanto que $O$. lanceolata possui lâminas foliares com margens inteiras (raramente serreadas apenas no ápice), base sempre obtusa em todo o ramo e as superfícies opacas e frequentemente glaucas. Ouratea lancifolia também pode ser semelhante a O. floribunda (A. St.-Hil.) Engl. que, conforme observamos nos herbários e no campo, pode variar quanto ao hábito (geralmente subarbustivo mas ocasionalmente arbustivo), tamanho da inflorescência e, tamanho, forma (mais elíptica ou mais oblonga), margem das folhas (crenado-serreadas ou serreadas) e superfície foliar (opaca ou brilhante mas não glauca). Os indivíduos de O. floribunda apresentam folhas com margens serreadas e, assim, assemelham-se às de $O$. lancifolia. Porém, $O$. lancifolia possui folhas cordadas na base (sempre obtusa em $O$. floribunda), inflorescências glabras (vs. com tricomas papilosos), bractéolas menores, $c a$. 2-2,5 mm compr. (vs. 3,5 mm compr.), assim como os botões florais 4-5 $\mathrm{mm}$ (vs. 8,5 mm compr.) e o estilete 4-5 mm compr. (vs. 66,5 mm compr.), e anteras rugulosas sem protuberâncias nas rugas (vs. com protuberâncias).

Assim, O. lancifolia se distingue das espécies morfologicamente mais próximas pela combinação de forma, base e margem da folha, acrescida de outros caracteres (aspecto da superfície foliar, tamanho e morfologia de algumas estruturas florais).
Agradecimentos - Ao CNPq e à Funarbe, pelas bolsas concedidas em períodos distintos do Mestrado; aos curadores dos herbários citados, pelos empréstimos concedidos; ao Prof. Odaci de Oliveira, pela diagnose latina.

\section{Referências}

CHACON, R.G., YAMAMOTO, K. \& CAVALCANTI, T.B. 2003. Ochnaceae. In Flora do Distrito Federal, Brasil. (T.B. Cavalcanti \& A.E. Ramos, orgs.). Stilo Gráfica e Editora, Brasília, v.3, p.206-226.

CHACON, R.G. \& YAMAMOTO, K. 2010. Ouratea Aubl. Ochnaceae. In Catálogo de plantas e fungos do Brasil. (R.C. Forzza et al., orgs.). Andrea Jakobsson Estúdio, Rio de Janeiro, v.2, p.1334-1337.

ENGLER, A. 1876. Ochnaceae. In Flora Brasiliensis. (C.F.P. Martius, A.G. Eichler \& I. Urban, eds.). Monachii, Frid. Fleischer 12:297-366, tab. 62-77.

FIASCHI, P., NICOLETTI, C.F. \& YAMAMOTO, K. 2011. Ochnaceae. In Neotropikey - Interactive key and information resources for flowering plants of the Neotropics. (W. Milliken, B. Klitgaard \& A. Baracat, orgs.). www.kew.org/neotropikey (acesso em 30/11/2011).

IUCN. 2003. Guidelines for application of IUCN Red List criteria at regional levels. Version 3.0. IUCN Species survival commission. IUCN, Gland and Cambridge.

YAMAMOTO, K., CHACON, R.G., PROENÇA, C.E.B., CAVALCANTI, T.B. \& RIBEIRO, D.G. 2008. A distinctive new species of Ouratea (Ochnaceae) from the Jalapão Region, Tocantins, Brazil. Novon 18:397-404. 